\title{
Efficacy and safety of bupropion in cancer- related fatigue, a randomized double blind placebo controlled clinical trial
}

\author{
Ebrahim Salehifar ${ }^{1 *}$, Saeid Azimi ${ }^{2}$, Ghasem Janbabai $^{3}$, Ehsan Zaboli ${ }^{3}$, Narjes Hendouei $^{2}$, Fatemeh Saghafi ${ }^{4}$ and \\ Samaneh Borhani ${ }^{5}$
}

\begin{abstract}
Background and objectives: Cancer-related fatigue (CRF) is one of the most prevalent complications experienced by cancer patients during and after the process of treatment. Despite conducting a lot of studies, there is no approved therapy to help manage CRF. This study aims to investigate the efficacy of bupropion on CRF.

Materials and methods: In this double-blind randomized placebo-controlled clinical trial, a total of 30 eligible cancer patients suffering from fatigue were randomly divided into two groups (15 patients in each group). Bupropion was administered $75 \mathrm{mg} /$ day for the first three days and $150 \mathrm{mg} /$ day (divided in two doses) till the end of the study at week 6. Fatigue as the primary outcome was measured by BFI (Brief Fatigue Inventory) and FACITFatigue (Functional Assessment of Chronic Illness Therapy) scales. Secondary outcomes included HADS (Hospital Anxiety and Depression Scale) and performance status (PS) measured by Karnofsky and ECOG (Eastern Cooperative Oncology Group) scales. Assessments were done at baseline, end of the second and sixth week.

Results: There was no significant difference between placebo and bupropion at baseline and the end of second week. Significant difference was seen between two groups at the end of week six ( $P=0.006$ based on BFI) in favor of bupropion. In-group assessment showed improvement in fatigue levels in both groups during study time $(P=$ 0.000 based on BFI for both bupropion and placebo). Secondary outcomes (e.g., HADS and PS) were not different at baseline and the end of second week. However, at the end of week six, the difference was significant in favor of bupropion.
\end{abstract}

Conclusion: A six-week trial of bupropion reduces the CRF and improves the PS of cancer patients. Trial registration: Current Controlled Trials IRCT20090613002027N12, registration date: 2018-06-01.

Keywords: Fatigue, Cancer-related fatigue, Bupropion, Performance status, Clinical trial

\section{Introduction}

Cancer-related fatigue (CRF) is one of the most common and bothersome side effects among cancer patients. It can be associated with the cancer itself, cancer treatment, and/ or other symptoms such as depression or poor sleep [1]. CRF is a distressing, persistent and subjective sense of physical, emotional, and/or cognitive tiredness or exhaustion related to cancer or cancer therapy which is not proportional to recent activities and interferes with usual

\footnotetext{
*Correspondence: Esalehifar@mazums.ac.ir; Esalehifar52@gmail.com ${ }^{1}$ Pharmaceutical Research Center, Faculty of Pharmacy, Mazandaran University of Medical Sciences, Sari, Iran

Full list of author information is available at the end of the article
}

functioning. Compared with the fatigue experienced by healthy individuals, CRF is more severe, more distressing and less likely to be relieved by rest $[2,3]$.

The prevalence of CRF is not exactly estimated but some studies claim that about $59-96 \%$ of patients undergoing chemotherapy and $65-100 \%$ of patients undergoing radiotherapy will experience CRF. CRF can affect patient's life and quality of life and because of its severity compared with usual fatigue, some patients might not continue the treatment [4-6].

The reasons of CRF occurrence and effecting factors are not clear yet but in every patient, CRF is related to dysregulation of biochemical and physiological systems

(c) The Author(s). 2020 Open Access This article is distributed under the terms of the Creative Commons Attribution 4.0 International License (http://creativecommons.org/licenses/by/4.0/), which permits unrestricted use, distribution, and reproduction in any medium, provided you give appropriate credit to the original author(s) and the source, provide a link to the Creative Commons license, and indicate if changes were made. The Creative Commons Public Domain Dedication waiver (http://creativecommons.org/publicdomain/zero/1.0/) applies to the data made available in this article, unless otherwise stated. 
of body. There are lots of studies focusing on CRF and effecting factors such as the cancer itself, treatments that patient receives (surgery, chemotherapy, radiotherapy, hormone therapy) and also chronic physical and mental situations like anemia, pain, depression, anxiety, cachexia and sleep disorders [7].

Several mechanisms including dysregulation in the function of cytokines, dysregulation in hypothalamic-pituitaryadrenal axis function, disruption in circadian rhythm, activation of vagal afferent nerve, serotonin dysregulation, changes in muscle metabolism, adenosine triphosphate dysregulation and contractile properties have been proposed for CRF $[8,9]$. Dysregulation in the release of cytokines may play an important role in the development of CRF by means of inflammation. This is somehow related to chronic inflammatory processes caused by $\mathrm{T}$ lymphocytes [7]. Some therapeutic approaches, such as radiotherapy or chemotherapy, may also increase the levels of these cytokines [10,11].

The HPA axis naturally regulates cortisol release which is responsible for Inhibition of cytokine release and controlling inflammation. In chronic inflammatory conditions such as cancer, which increases the production of inflammatory biomarkers, the HPA axis stimulation and cortisol activity decreases, leading to more inflammatory effects and developing fatigue [2].

Circadian rhythm disruption may cause cytokine dysregulation and developing CRF $[2,12]$. Cancer can increase the release of serotonin in brain, which in turn increases the upregulation of serotonin receptors. This can lead to decrease in physical activity capacity. Activation of the vagal afferent nerve due to the release of cytokines, prostaglandins and other compounds can reduce somatomotor activity and lead to fatigue. Decreased ATP production and subsequently increased metabolic byproducts can also lead to fatigue $[2,7,13]$.

Some medical and nonmedical approaches have been evaluated in CRF. L-carnitine as a medical supplement, psychological interventions and stress management plans individually or while in groups are some examples of the interventions $[14,15]$. In some studies exercise and aerobic practices have been considered. Exercise can reduce CRF and is effective in improvement of muscular and breathing condition of patients [16-18]. Efficacy of exercise was more prominent in some solid tumors (breast or prostate cancer) compared with blood malignancies [1922]. It seems that using exercise for reducing CRF needs more studies [16, 17]. Yoga, acupuncture, massage therapy and music therapy are other nonmedical methods for management of CRF [23-27].

Along with nonmedical therapies, several medical agents were investigated in reducing the fatigue in cancer patients. Herbals such as Panax quinquefolius [28, 29], Withania somnifera [30] or Chinese traditional herbals [31, 32] haven't been able to make significant effects on CRF.
Among the chemical compounds, most studies have focused on the use of brain stimulants, blood growth factors, antidepressants, as well as progesterone [33].

Bupropion has been tested on fatigue of the cancer patients in some limited studies [34, 35]. Bupropion is a second generation antidepressant with atypical structure and has been approved for treatment of depression and smoking cessation [36]. Bupropion has been shown to be effective on fatigue of patients suffering from multiple sclerosis [37], anxiety disorders [38] and fatigue syndrome [39] and there is the possibility to be effective in CRF. Immediate-release (IR) bupropion can cause headache, insomnia, nausea/vomiting, agitation, dry mouth, constipation, tremor and seizure $[40,41]$.

We conducted this study to evaluate the efficacy of bupropion in CRF.

\section{Methods}

\section{Patients}

This randomized double-blind placebo-controlled clinical trial was done in Tooba Clinic, affiliated to Mazandaran University of Medical Sciences from September 2017 to August 2018. From 79 patients, 30 eligible patients suffering from CRF were assigned to study groups. Inclusion criteria was fatigue score of at least 4 out of 10 based on Brief Fatigue Inventory scale (BFI) [42] lasted for at least one week with no reasons. Exclusion criteria were age younger than 18, history of using CNS stimulants or antidepressants, history of epilepsy, usage of erythropoietin in the last six weeks, fatigue before cancer diagnosis, performance status score $\leq 50$ based on Karnofsky performance scale, history of suicide, use of monoamine oxidase inhibitors (MAOIs) during the last two weeks, liver insufficiency (transaminases three times the upper limit of normal), kidney impairment (creatinine clearance $<60 \mathrm{ml} /$ $\mathrm{min}$ ) and pregnancy/breast feeding.

\section{Study design}

Patients were randomly divided into two groups based on random number table: bupropion group $(n=15)$ and control group $(n=15)$. For bupropion group, bupropion was administered $75 \mathrm{mg} /$ day for the first three days and 150 $\mathrm{mg} /$ day $(75 \mathrm{mg} / \mathrm{BID})$ for the rest of the study. Control group received placebo instead of bupropion with the same conditions. The study was six weeks long and assessments were done at baseline and end of the week two and six.

\section{Data gathering}

Demographic and clinical information of patients were recorded at the beginning of the study. Fatigue was the primary outcome and was measured by BFI and Functional Assessment of Chronic Illness Therapy (FACIT-fatigue) scale [43]. Anxiety/depression was assessed by Hospital Anxiety and Depression Scale (HADS) and performance 


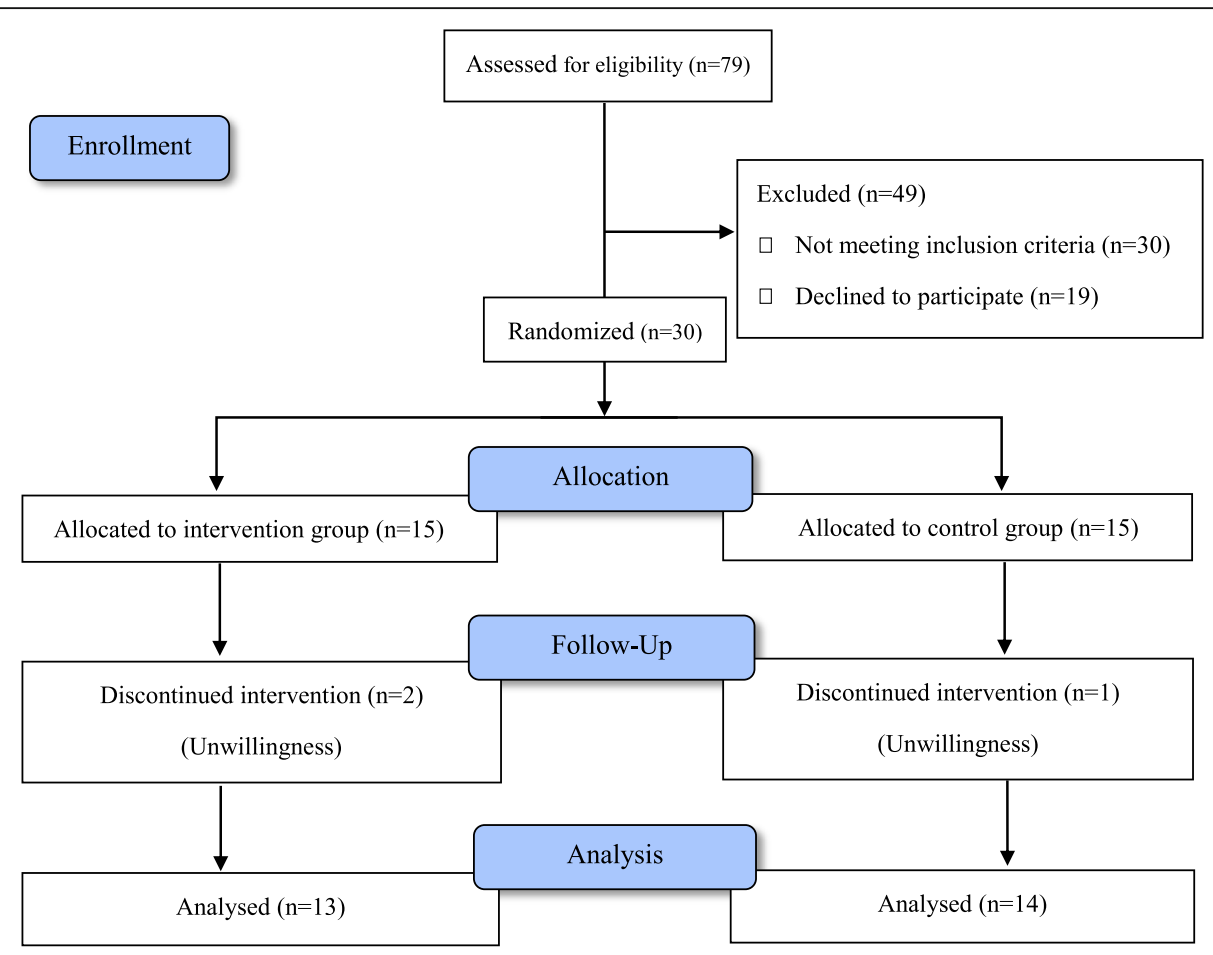

Fig. 1 Flowchart of the study

status (PS) was evaluated by Eastern Cooperative Oncology Group (ECOG) PS scale and Karnofsky PS scale. HADS scale is a two-section scale including 14 questions ( 7 for anxiety and 7 for depression) and for each questions, 0 to 3 points are considered. The score $\geq 9$ for each section means that patient has anxiety or depression [44]. ECOG is a brief questionnaire consisting of five conditions (scoring from 0 to 4 ) that based on the patient's status, one of these conditions will be chosen. The higher scores mean poorer performance status [45]. Karnofsky PS scale is similar to ECOG but its range of scaling is from 0 to 100 [46]. Statistical analysis was performed using SPSS software. Quantitative and qualitative variables were compared using independent $\mathrm{t}$-test and chi-square test, respectively. Repeated Measure ANOVA was used to compare quantitative means in each group. All the adverse effects were categorized and recorded based on NCI common terminology criteria for adverse events [47]. Risk of seizure incidence during chemotherapy, nausea/vomiting and dry mouth were considered [48-51].

\section{Results}

79 patients were assessed for eligibility. 30 patients did not fulfill the study criteria and 19 declined to participate. 30 patients were randomly assigned to receive bupropion or placebo. 14 patients in control group and 13 patients in bupropion group finished the 6-week duration of the study (Fig. 1).

Demographic and clinical characteristics of patients have been shown in Table 1. The groups were not different

Table 1 Demographic and clinical features of patients

\begin{tabular}{|c|c|c|c|c|}
\hline & & Placebo & Bupropion & $\begin{array}{l}P \text { - } \\
\text { value }\end{array}$ \\
\hline \multicolumn{2}{|c|}{ Age (mean \pm standard division) } & $\begin{array}{l}60.21 \pm \\
9.9\end{array}$ & $\begin{array}{l}53.69 \pm \\
12.87\end{array}$ & 0.15 \\
\hline \multirow[t]{2}{*}{ Sex (number) } & Male & 7 & 4 & 0.31 \\
\hline & Female & 7 & 9 & \\
\hline \multirow[t]{5}{*}{$\begin{array}{l}\text { Diagnosis } \\
\text { (number) }\end{array}$} & $\begin{array}{l}\text { Breast } \\
\text { cancer }\end{array}$ & 5 & 5 & 0.94 \\
\hline & $\begin{array}{l}\text { Colorectal } \\
\text { cancer }\end{array}$ & 4 & 3 & \\
\hline & $\begin{array}{l}\text { Prostate } \\
\text { cancer }\end{array}$ & 2 & 2 & \\
\hline & $\begin{array}{l}\text { Gastric } \\
\text { cancer }\end{array}$ & 2 & 1 & \\
\hline & $\begin{array}{l}\text { Other } \\
\text { cancers }\end{array}$ & 1 & 2 & \\
\hline \multirow{3}{*}{$\begin{array}{l}\text { Other treatments } \\
\text { (number) }\end{array}$} & Radiotherapy & 7 & 4 & 0.33 \\
\hline & Surgery & 5 & 4 & \\
\hline & $\begin{array}{l}\text { Radiotherapy } \\
+ \text { surgery }\end{array}$ & 2 & 5 & \\
\hline
\end{tabular}


Table 2 Mean scores of BFI and FACIT in cancer patients during the study

\begin{tabular}{|c|c|c|c|c|c|c|c|}
\hline \multirow[t]{2}{*}{ (A) } & \multirow[t]{2}{*}{ (B) } & & \multirow{2}{*}{$\begin{array}{l}\text { Mean } \\
\text { difference } \\
\text { (A-B) }\end{array}$} & \multirow[t]{2}{*}{ SE } & \multicolumn{2}{|c|}{ 95\% Confidence interval of difference } & \multirow{2}{*}{$\begin{array}{l}P \text { - } \\
\text { value }\end{array}$} \\
\hline & & & & & Lower & Upper & \\
\hline \multirow[t]{4}{*}{ Baseline (BFI) } & \multirow{2}{*}{$\begin{array}{l}\text { End of 2nd } \\
\text { week (BFI) }\end{array}$} & Placebo & 0.16 & 0.06 & 0.03 & 0.3 & 0.017 \\
\hline & & Bupropion & 0.64 & 0.16 & 0.27 & 1 & 0.002 \\
\hline & \multirow{2}{*}{$\begin{array}{l}\text { End of } \sigma_{\mathrm{th}} \\
\text { week }(\mathrm{BFI})\end{array}$} & Placebo & 0.49 & 0.1 & 0.27 & 0.7 & $0.001>$ \\
\hline & & Bupropion & 1.8 & 0.17 & 1.8 & 2.2 & $0.001>$ \\
\hline \multirow[t]{2}{*}{ End of $2_{\text {nd }}$ week $(\mathrm{BFI})$} & \multirow{2}{*}{$\begin{array}{l}\text { End of } \sigma_{\text {th }} \\
\text { week }(B F I)\end{array}$} & Placebo & 0.3 & 0.11 & 0.08 & 0.56 & 0.01 \\
\hline & & Bupropion & 1.16 & 0.14 & 0.8 & 1.4 & $0.001>$ \\
\hline \multirow[t]{4}{*}{ Baseline (FACIT) } & \multirow{2}{*}{$\begin{array}{l}\text { End of } 2_{n d} \\
\text { week (FACIT) }\end{array}$} & Placebo & -0.57 & 0.7 & -2.1 & 0.9 & 0.4 \\
\hline & & Bupropion & -3.15 & 0.67 & -6.4 & -1.67 & 0.001 \\
\hline & \multirow{2}{*}{$\begin{array}{l}\text { End of } \sigma_{\text {th }} \\
\text { week (FACIT) }\end{array}$} & Placebo & -1.8 & 1 & -4 & 0.3 & 0.09 \\
\hline & & Bupropion & -7 & 0.9 & -9 & -5 & $0.001>$ \\
\hline \multirow[t]{2}{*}{ End of $2_{\text {nd }}$ week (FACIT) } & \multirow{2}{*}{$\begin{array}{l}\text { End of } \sigma_{\text {th }} \\
\text { week (FACIT) }\end{array}$} & Placebo & -1.28 & 1.2 & -4 & 1.4 & 0.2 \\
\hline & & Bupropion & -3.9 & 0.5 & -5 & -2.7 & $0.001>$ \\
\hline
\end{tabular}

regarding age, sex, and cancer diagnosis and treatment modalities.

\section{Primary outcomes}

The results of BFI and FACIT-fatigue questionnaires have been reported in Table 2. For BFI, there wasn't any significant difference between placebo group and bupropion group at baseline $(P=0.3)$ and the end of second week $(P=0.8)$ while there was a significant difference at the end of week six $(P=0.006)$. For FACIT-fatigue scale, there were no significant differences at any periods of the study, however, the mean scores of fatigue for bupropion group were better.

In Table 3, Mean difference of fatigue scores in both placebo and bupropion groups has been reported. The BFI score mean difference in all periods of time was significant for both placebo and bupropion groups. For FACIT, there was no difference between mean scores for placebo, however differences between baseline and second week and sixth week were significant for bupropion group $(P=0.001$ and $P>0.001$, respectively).

\section{Secondary outcomes}

In Table 4, mean scores of depression and anxiety have been shown. Except mean score of depression at the week $6(P=0.03)$, there was no difference between placebo and bupropion in case of anxiety and depression.

For bupropion group, all mean differences of HADS for both anxiety and depression domains were statistically significant at the end of weeks 2 and 6 compared with baseline. Significant differences between mean scores of anxiety/depression at baseline and the end of sixth weeks $(P=0.009$ and $P<0.001)$ and between the end of the second and sixth weeks were observed $(P=0.014$ and $P=0.002)$ for placebo group (Table 5).

Performance status of patients was evaluated using both ECOG and Karnofsky tools (Table 6).

For performance status, the significant difference was seen at the end of the six weeks for placebo and bupropion groups based on both ECOG and Karnofsky scale ( $P>0.001$ for ECOG and $P=0.01$ for Karnofsky scales, respectively). For ECOG, no difference was seen between mean scores of placebo at any time periods of study but for bupropion group, baseline and sixth weeks $(P<$

Table 3 Mean difference of fatigue scores

\begin{tabular}{|c|c|c|c|c|c|c|c|c|}
\hline \multirow[t]{2}{*}{$\mathrm{BFI}$} & & \multirow[b]{2}{*}{ Number } & \multirow[b]{2}{*}{ mean \pm standard division } & \multirow[b]{2}{*}{ SE } & \multirow[b]{2}{*}{$P$-value } & \multicolumn{2}{|l|}{ FACIT } & \multirow[b]{2}{*}{$P$-value } \\
\hline & & & & & & mean \pm standard division & SE & \\
\hline \multirow[t]{2}{*}{ Baseline } & Placebo & 14 & $5.4 \pm 0.6$ & 0.16 & 0.3 & $24.6 \pm 7.5$ & 2 & 0.6 \\
\hline & Bupropion & 13 & $5.8 \pm 1.2$ & 0.3 & & $23.15 \pm 7.2$ & 2 & \\
\hline \multirow[t]{2}{*}{ End of $2_{\text {nd }}$ week } & Placebo & 14 & $5.3 \pm 0.5$ & 0.14 & 0.8 & $25.2 \pm 7$ & 1.8 & 0.7 \\
\hline & Bupropion & 13 & $5.2 \pm 1.3$ & 0.36 & & $26.3 \pm 7.3$ & 2 & \\
\hline \multirow[t]{2}{*}{ End of $\sigma_{\text {th }}$ week } & Placebo & 14 & $4.9 \pm 0.7$ & 0.19 & 0.006 & $26.5 \pm 6.8$ & 1.8 & 0.15 \\
\hline & Bupropion & 13 & $4 \pm 0.9$ & 0.25 & & $30.2 \pm 6.1$ & 1.7 & \\
\hline
\end{tabular}


Table 4 Mean scores of hospital anxiety and depression score (HADS) during the study period

\begin{tabular}{|c|c|c|c|c|c|c|c|c|}
\hline \multicolumn{6}{|l|}{ HADS (Anxiety) } & \multicolumn{3}{|l|}{ HADS (Depression) } \\
\hline & & Number & mean \pm standard division & SE & $P$-value & mean \pm standard division & SE & $P$-value \\
\hline \multirow[t]{2}{*}{ Baseline } & Placebo & 14 & $8.5 \pm 2.8$ & 0.76 & 0.7 & $7 \pm 3.1$ & 0.83 & 0.77 \\
\hline & Bupropion & 13 & $9 \pm 3$ & 0.8 & & $5.7 \pm 2.5$ & 0.7 & \\
\hline \multirow[t]{2}{*}{ End of $2_{\text {nd }}$ week } & Placebo & 14 & $8.2 \pm 2.5$ & 0.68 & 0.8 & $6.4 \pm 2.9$ & 0.79 & 0.13 \\
\hline & Bupropion & 13 & $8 \pm 2.7$ & 0.77 & & $4.7 \pm 2.4$ & 0.69 & \\
\hline \multirow[t]{2}{*}{ End of $\sigma_{\text {th }}$ week } & Placebo & 14 & $6.5 \pm 0.6$ & 0.7 & 0.22 & $4.7 \pm 2.5$ & 0.68 & 0.03 \\
\hline & Bupropion & 13 & $5.3 \pm 1.8$ & 0.5 & & $2.8 \pm 1.7$ & 0.47 & \\
\hline
\end{tabular}

$\mathrm{HADS}_{\mathrm{A}}$ Hospital Anxiety and Depression Scale (Anxiety).

HADSD Hospital Anxiety and Depression Scale (Depression).

$0.001)$ and second and sixth weeks data were significant $(\mathrm{P}<0.001)$. Regarding Karnofsky scale, between baseline and the end of second week, there was no significant difference between mean scores for both groups. The most change in mean scores was for the end of week six. This change wasn't statistically significant for placebo group while it was significantly improved in bupropion group. The change in mean scores of performance status was significant for bupropion group at the end of week six $(P<0.001)$ (Table 7).

\section{Discussion}

In this study, the efficacy of bupropion in CRF was assessed. The results showed that the more approaching to the end of study, the more effective bupropion gets and the mean scores of patients received bupropion were generally better than patients treated with placebo particularly at the end of the study. Considering BFI scores, bupropion was associated with a better efficacy compared with placebo over the time. Based on FACITfatigue scale, although no significant difference was seen between bupropion and placebo, the scores were higher, i.e. better, in patients on bupropion than in the placebo group. A similar result was seen in the study of Moss et al. in 2006. In their research, effects of bupropion SR on fatigue, depression and quality of life of mixed-site cancer patients was studied. 21 patients were divided into 2 groups of "depressed" and "non-depressed" and bupropion was administered for them (open-label).After one month, the assessments showed that bupropion improved the symptoms of fatigue and depression [34]. In another study performed by Cullum et al. in 2004, improvement in fatigue scores was seen two to four weeks after the beginning of the study [35]. Also in the study of Ashrafi et al. bupropion was helpful for decreasing CRF. They used $150 \mathrm{mg}$ bupropion SR once a day. Based on the results of this 4 week study, bupropion showed improvement in fatigue levels of intervention group in comparison to placebo arm, however, small size of sample in the study ( 40 patients) was a limit to establish a strong relationship between use of bupropion and fatigue improvement. The safety of the drug during the

Table 5 Mean difference of Anxiety and Depression scores in both placebo and bupropion group

\begin{tabular}{|c|c|c|c|c|c|c|c|}
\hline \multirow[t]{2}{*}{ (A) } & \multirow[t]{2}{*}{ (B) } & & \multirow[t]{2}{*}{ Mean difference (A-B) } & \multirow[t]{2}{*}{ SE } & \multicolumn{2}{|c|}{ 95\% Confidence interval of difference } & \multirow[t]{2}{*}{$P$-value } \\
\hline & & & & & Lower & Upper & \\
\hline \multirow[t]{4}{*}{ Baseline $\left(\mathrm{HADS}_{\mathrm{A}}\right)$} & End of 2nd week (HADSA) & Placebo & 0.37 & 0.28 & -0.26 & 0.98 & 0.2 \\
\hline & & Bupropion & 1 & 0.3 & 0.3 & 1.7 & 0.009 \\
\hline & End of 6th week (HADSA) & Placebo & 2.07 & 0.67 & 0.6 & 3.5 & 0.009 \\
\hline & & Bupropion & 3.6 & 0.5 & 2.5 & 4.7 & $0.001>$ \\
\hline \multirow[t]{2}{*}{ End of 2nd week (HADSA) } & End of 6th week (HADSA) & Placebo & 1.7 & 0.6 & 0.4 & 3 & 0.014 \\
\hline & & Bupropion & 2.6 & 0.4 & 1.7 & 3.48 & $0.001>$ \\
\hline \multirow[t]{4}{*}{ Baseline (HADSD) } & End of 2nd week (HADSD) & Placebo & 0.57 & 0.29 & -0.05 & 1.2 & 0.07 \\
\hline & & Bupropion & 1 & 0.25 & 0.4 & 1.5 & 0.002 \\
\hline & End of 6th week (HADSD) & Placebo & 2.2 & 0.42 & 1.3 & 3.1 & $0.001>$ \\
\hline & & Bupropion & 2.9 & 0.4 & 2 & 3.8 & $0.001>$ \\
\hline \multirow[t]{2}{*}{ End of 2nd week (HADSD) } & End of 6th week (HADSD) & Placebo & 1.64 & 0.4 & 0.7 & 2.5 & 0.002 \\
\hline & & Bupropion & 1.9 & 0.38 & 1 & 2.7 & $0.001>$ \\
\hline
\end{tabular}

$\mathrm{HADS}_{\mathrm{A}}$ Hospital Anxiety and Depression Scale (Anxiety). HADSD Hospital Anxiety and Depression Scale (Depression). 
Table 6 Mean scores of performance status

\begin{tabular}{|c|c|c|c|c|c|c|c|c|}
\hline \multirow{2}{*}{ ECOG } & & \multirow[b]{2}{*}{ Number } & \multirow[b]{2}{*}{ mean \pm standard division } & \multirow[b]{2}{*}{ SE } & \multirow[b]{2}{*}{ P-value } & \multicolumn{2}{|l|}{ Karnofsky } & \multirow[b]{2}{*}{$P$-value } \\
\hline & & & & & & mean \pm standard division & SE & \\
\hline \multirow[t]{2}{*}{ Baseline } & Placebo & 14 & $1.7 \pm 0.4$ & 0.11 & 0.9 & $67.14 \pm 6.1$ & 1.6 & 0.9 \\
\hline & Bupropion & 13 & $1.7 \pm 0.4$ & 0.11 & & $66.9 \pm 8.5$ & 2.3 & \\
\hline \multirow[t]{2}{*}{ End of $2_{\text {nd }}$ week } & Placebo & 14 & $1.7 \pm 0.4$ & 0.11 & 0.3 & $67.1 \pm 6.1$ & 1.6 & 0.5 \\
\hline & Bupropion & 13 & $1.6 \pm 0.5$ & 0.14 & & $69.2 \pm 9.5$ & 2.6 & \\
\hline \multirow[t]{2}{*}{ End of $\sigma_{\text {th }}$ week } & Placebo & 14 & $1.6 \pm 0.5$ & 0.13 & $0.001>$ & $70 \pm 9.6$ & 2.5 & 0.01 \\
\hline & Bupropion & 13 & $0.9 \pm 0.27$ & 0.7 & & $79.2 \pm 7.5$ & 2.1 & \\
\hline
\end{tabular}

study was reported as no seizures were seen and bupropion was well-tolerated by patients [52].

Some other agents such as methylphenidate, modafinil and donepezil have been evaluated in patients with CRF but the results of these studies were not encouraging. Siu et al. in 2013 examined the efficacy of methylphenidate in reducing CRF. Results of this study showed better improvement in CRF only in patients younger than 60 [53]. In Jean-pierre's study, patients with mild to moderate fatigue did not show improvement whereas patients with severe fatigue did [54]. Moraska et al. reported that methylphenidate did not improve BFI and the quality of life of patients with CRF when compared with placebo, but in a subset of patients with severe fatigue and/or more advanced disease, it was helpful [55]. In an open label trial, donepezil was not superior to placebo in patients with CRF [56]. Modafinil may be a more promising drug for CRF, but in a randomized clinical trial, it was associated with only modest improvement in docetaxel-related fatigue [57]. It seems that the results of bupropion for the management of CRF in our study are hopeful.

We included HADS score and performance status as the secondary outcomes in our trial. Considering the depression domain, mean scores of depression at the end of week 6 was more favorable in patients who received bupropion. Mean scores of depression before week 6 and also anxiety scores during the whole 6 weeks of study were not significantly different between placebo and bupropion group. Other antidepressants also have been used for CRF. In a study, paroxetine $30 \mathrm{mg}$ for 7 days was administered to reduce the symptoms of fatigue and depression in cancer patients. Paroxetine reduced depression but was associated with a lack of efficacy in reducing fatigue score [58]. Other agents such as coenzyme Q10 was also examined in breast-cancer patients experienced fatigue. It showed no efficacy in reducing the fatigue and depression of breast-cancer patients $[59,60]$.

Performance status of patients improved during the study but this improvement was more obvious in bupropion group. In both ECOG and Karnofsky scales, the most changes in scores were seen during the final week of the study. In an open-label 4-week trial, Blackhall et al. reported that modafinil improved HADS scores, CRF and ECOG performance status [61]. Improving performance status along with fatigue scores confirms the

Table 7 Mean difference of performance status scores

\begin{tabular}{|c|c|c|c|c|c|c|c|}
\hline \multirow[t]{2}{*}{ (A) } & \multirow[t]{2}{*}{ (B) } & & \multirow{2}{*}{$\begin{array}{l}\text { Mean } \\
\text { difference } \\
\text { (A-B) }\end{array}$} & \multirow[t]{2}{*}{ SE } & \multicolumn{2}{|c|}{ 95\% Confidence interval of difference } & \multirow{2}{*}{$\begin{array}{l}P_{-} \\
\text {value }\end{array}$} \\
\hline & & & & & Lower & Upper & \\
\hline \multirow[t]{4}{*}{ Baseline (ECOG) } & End of $2_{\text {nd }}$ week (ECOG) & Placebo & 0 & 0 & 0 & 0 & 0 \\
\hline & & Bupropion & 0.15 & 0.1 & -0.07 & 0.38 & 0.16 \\
\hline & End of $\sigma_{\text {th }}$ week (ECOG) & Placebo & 0.14 & 0.09 & -0.06 & 0.3 & 0.16 \\
\hline & & Bupropion & 0.8 & 0.1 & 0.6 & 1.07 & $0.001>$ \\
\hline \multirow[t]{2}{*}{ End of $2_{\text {nd }}$ week (ECOG) } & End of $\sigma_{\text {th }}$ week (ECOG) & Placebo & 0.14 & 0.09 & -0.067 & 0.3 & 0.16 \\
\hline & & Bupropion & 0.7 & 0.13 & 0.4 & 0.98 & $0.001>$ \\
\hline \multirow[t]{4}{*}{ Baseline (Karnofsky) } & End of $2_{\text {nd }}$ week (Karnofsky) & Placebo & 0 & 0 & 0 & 0 & - \\
\hline & & Bupropion & -2.3 & 1.2 & -4.9 & 0.3 & 0.08 \\
\hline & End of $\sigma_{\text {th }}$ week (Karnofsky) & Placebo & -2.8 & 1.6 & -6.38 & 0.67 & 0.1 \\
\hline & & Bupropion & -12.3 & 1.2 & -14.9 & -9.6 & $0.001>$ \\
\hline \multirow[t]{2}{*}{ End of $2_{\text {nd }}$ week (Karnofsky) } & End of $\sigma_{\text {th }}$ week (Karnofsky) & Placebo & -2.8 & 1.6 & -6.38 & 0.67 & 0.1 \\
\hline & & Bupropion & -10 & 1.1 & -12.4 & -7.5 & $0.001>$ \\
\hline
\end{tabular}


relationship between fatigue and performance of cancer patients [62] .

In our trial, the side effect profile of bupropion was acceptable. Only two patients complained of lack of appetite and insomnia and none of the patients left the study due to adverse effects. Some studies have shown that bupropion has a favorable side effect profile because almost all adverse effects reported were mild or moderate and less than $10 \%$ of patients did not continue the study due to adverse events. In addition, it does not pose the risk of abuse contrary to some agents like methylphenidate or amphetamines [34, 40, 41].

The small sample size and high dropout rate relative to the number of patients entered (10\% overall and $13 \%$ in the bupropion arm) were of limitations of this study. Small sample size would influence the relationship between the use of bupropion and improvement in CRF as Ashrafi et al. mentioned in their study and also would make it difficult to identify subgroups that benefit more. The reason why some patients exited during the study was lack of desire which may show their few information about cancer therapy and because of the uncertainty over the effects of bupropion, they left the study. More studies with larger sample size are needed to be carried out to overcome these problems.

\section{Conclusion}

Administration of bupropion $150 \mathrm{mg} /$ day was effective in the management of CRF in a six-week trial. In addition to CRF, bupropion was associated with improvement in depression domain of HADS and also significantly improved performance status of cancer patients.

\section{Abbreviations \\ BFI: Brief Fatigue Inventory; CRF: Cancer-Related Fatigue; ECOG: Eastern Cooperative Oncology Group; FACIT: Functional Assessment of Chronic Illness Therapy; HADS: Hospital Anxiety and Depression Scale; MAOI: Monoamine Oxidase Inhibitor; NCl: National Cancer Institute; PS: Performance status}

\section{Acknowledgements}

This article is derived from the thesis Efficacy and safety of bupropion in cancer-related fatigue, a randomized double blind placebo controlled clinical trial' supervised by Professor Ebrahim Salehifar and submitted by Dr. Fatemeh Saghafi to the Faculty of Pharmacy of Mazandaran University of Medical Sciences, Sari, Iran, in partial fulfillment of the requirements for the Degree of Pharm-D of Saeid Azimi.

\section{Authors' contributions}

Conception and design: ES, SA and NH. Data collection: SA, GJ, EZ and SB. Data analysis and manuscript preparation: ES, SA and FS. Final approval of manuscript: All authors.

\section{Funding}

This study was financially supported by a grant from the Research and Technology Department of Mazandaran University of Medical Sciences (grant no. 95102), Sari, Iran. This grant providing funding to give medical agents, data analysis and editorial assistance with the writing of the manuscript but had no role in study design and data collection.

\section{Availability of data and materials}

All data generated or analyzed during this study are included in this published article.

\section{Ethics approval and consent to participate}

All patients signed an informed consent form prior to participation in the study. The study was approved by the Ethics Committee of Mazandaran University of Medical Sciences, Sari, Iran (approval no.

IR.MAZUMS.REC.1396.3144) and registered in the Iranian Registry of Clinical Trials (IRCT20090613002027N12).

\section{Consent for publication}

Not applicable.

\section{Competing interests}

The authors declare that they have no competing interests regarding the publication of this paper.

\section{Author details}

${ }^{1}$ Pharmaceutical Research Center, Faculty of Pharmacy, Mazandaran University of Medical Sciences, Sari, Iran. ${ }^{2}$ Faculty of Pharmacy, Mazandaran University of Medical Sciences, Sari, Iran. ${ }^{3}$ Gastrointestinal Cancer Research Center, Faculty of Medicine, Mazandaran University of Medical Sciences, Sari, Iran. ${ }^{4}$ Faculty of Pharmacy, Shahid Sadoughi University of Medical Sciences, Yazd, Iran. ${ }^{5}$ Emam Khomeini Hospital, Mazandaran University of Medical Sciences, Sari, Iran.

Received: 6 September 2019 Accepted: 11 February 2020

Published online: 27 February 2020

\section{References}

1. Barsevick AM, Irwin MR, Hinds P, Miller A, Berger A, Jacobsen P, et al. Recommendations for high-priority research on cancer-related fatigue in children and adults. J Natl Cancer Inst. 2013;105(19):1432-40.

2. O'Higgins C, Brady B, O'Connor B, Walsh D, Reilly R. The pathophysiology of cancer-related fatigue: current controversies. Support Care Cancer. 2018:1-12.

3. Berger AM, Abernethy AP, Atkinson A, Barsevick AM, Breitbart WS, Cella D, et al. Cancer-related fatigue. J Natl Compr Cancer Netw. 2010;8(8):904-31.

4. Kiecolt-Glaser JK, Bennett JM, Andridge R, Peng J, Shapiro CL, Malarkey WB, et al. Yoga's impact on inflammation, mood, and fatigue in breast cancer survivors: a randomized controlled trial. J Clin Oncol. 2014;32(10):1040-9.

5. Zick SM, Harris RE, Sen A, Arnedt JT, Wyatt G, Foerster B, et al. Acupressure For Persistent Cancer Related Fatigue. Ann Arbor. 1001(48106):15.

6. Wang XS, Woodruff JF. Cancer-related and treatment-related fatigue. Gynecol Oncol. 2015;136(3):446-52.

7. Wang XS. Pathophysiology of cancer-related fatigue. Clin J Oncol Nurs. 2008;12(5 Suppl):11.

8. Ryan JL, Carroll JK, Ryan EP, Mustian KM, Fiscella K, Morrow GR. Mechanisms of cancer-related fatigue. Oncologist. 2007;12(Supplement 1):22-34.

9. Barsevick A, Frost M, Zwinderman A, Hall P, Halyard M. I'm so tired: biological and genetic mechanisms of cancer-related fatigue. Qual Life Res. 2010;19(10):1419-27.

10. Pusztai L, Mendoza TR, Reuben JM, Martinez MM, Willey JS, Lara J, et al. Changes in plasma levels of inflammatory cytokines in response to paclitaxel chemotherapy. Cytokine. 2004;25(3):94-102.

11. Linard C, Marquette C, Clarençon D, Galonnier M, Mathieu J, Pennequin A, et al. Acute ileal inflammatory cytokine response induced by irradiation is modulated by subdiaphragmatic vagotomy. J Neuroimmunol. 2005;168(12):83-95.

12. Sultan A, Choudhary V, Parganiha A. Worsening of rest-activity circadian rhythm and quality of life in female breast cancer patients along progression of chemotherapy cycles. Chronobiol Int. 2017;34(5):609-23.

13. Black DS, Cole SW, Christodoulou G, Figueiredo JC. Genomic mechanisms of fatigue in survivors of colorectal cancer. Cancer. 2018;124(12):2637-44.

14. Cruciani RA, Zhang JJ, Manola J, Cella D, Ansari B, Fisch MJ. L-carnitine supplementation for the management of fatigue in patients with cancer: an eastern cooperative oncology group phase III, randomized, double-blind, placebo-controlled trial. J Clin Oncol. 2012;30(31):3864-9.

15. Hayama $Y$, Inoue $T$. The effects of deep breathing on 'tension-anxiety' and fatigue in cancer patients undergoing adjuvant chemotherapy. Complement Ther Clin Pract. 2012;18(2):94-8. 
16. McMillan EM, Newhouse IJ. Exercise is an effective treatment modality for reducing cancer-related fatigue and improving physical capacity in cancer patients and survivors: a meta-analysis. Appl Physiol Nutr Metab. 2011;36(6): 892-903.

17. Velthuis M, Agasi-Idenburg S, Aufdemkampe G, Wittink H. The effect of physical exercise on cancer-related fatigue during cancer treatment: a metaanalysis of randomised controlled trials. Clin Oncol. 2010;22(3):208-21.

18. Puetz TW, Herring MP. Differential effects of exercise on Cancer-related fatigue during and following treatment: a meta-analysis. Am J Prev Med. 2012;43(2):e1-e24.

19. Cramp F, Byron-Daniel J. Exercise for the management of cancer-related fatigue in adults. Cochrane Database Syst Rev. 2012;(11):CD006145. https:// doi.org/10.1002/14651858.CD006145.pub3.

20. van Vulpen JK, Peeters PHM, Velthuis MJ, van der Wall E, May AM. Effects of physical exercise during adjuvant breast cancer treatment on physical and psychosocial dimensions of cancer-related fatigue: a meta-analysis. Maturitas. 2016:85:104-11.

21. Brown JC, Huedo-Medina TB, Pescatello LS, Pescatello SM, Ferrer RA, Johnson BT. Efficacy of exercise interventions in modulating cancer-related fatigue among adult cancer survivors: a meta-analysis. Cancer Epidemiol Prev Biomarkers. 2011;20(1):123-33.

22. Repka CP, Hayward R. Effects of an exercise intervention on Cancer-related fatigue and its relationship to markers of oxidative stress. Integr Cancer Ther. 2018;17(2):503-10.

23. Zhang $Y$, Lin L, Li H, Hu Y, Tian L. Effects of acupuncture on cancer-related fatigue: a meta-analysis. Support Care Cancer. 2018;26(2):415-25.

24. Pan $Y$, Yang $K$, Wang $Y$, Zhang L, Liang $H$. Could yoga practice improve treatment-related side effects and quality of life for women with breast cancer? A systematic review and meta-analysis. Asia Pac J Clin Oncol. 2017; 13(2):e79-95.

25. Lin P-J, Peppone $L$, Janelsins MC, Mohile SG, Kamen CS, Kleckner IR, et al. Yoga for the Management of Cancer Treatment-Related Toxicities. Curr Oncol Rep. 2018;20(1):5.

26. Kinkead B, Schettler PJ, Larson ER, Carroll D, Sharenko M, Nettles J, et al. Massage therapy decreases cancer-related fatigue: results from a randomized early phase trial. Cancer. 2018;124(3):546-54.

27. Alcântara-Silva TR, de Freitas-Junior R, Freitas NMA, de Paula Junior W, da Silva DJ, Machado GDP, et al. Music therapy reduces radiotherapy-induced fatigue in patients with breast or gynecological cancer: a randomized trial. Integr Cancer Ther. 2018;17(3):628-35.

28. Barton DL, Liu H, Dakhil SR, Linquist B, Sloan JA, Nichols CR, et al. Wisconsin ginseng (Panax quinquefolius) to improve cancer-related fatigue: a randomized, double-blind trial, N07C2. J Natl Cancer Inst. 2013;105(16): $1230-8$.

29. Barton DL, Soori GS, Bauer BA, Sloan JA, Johnson PA, Figueras C, et al. Pilot study of Panax quinquefolius (American ginseng) to improve cancer-related fatigue: a randomized, double-blind, dose-finding evaluation: NCCTG trial N03CA. Support Care Cancer. 2009;18(2):179

30. Biswal BM, Sulaiman SA, Ismail HC, Zakaria H, Musa Kl. Effect of Withania somnifera (Ashwagandha) on the development of chemotherapy-induced fatigue and quality of life in breast Cancer patients. Integr Cancer Ther. 2013;12(4):312-22.

31. Tamada S, Ebisu K, Yasuda S, Kato M, Ninomiya N, Yamasaki T, et al. Kamikihito improves cancer-related fatigue by restoring balance between the sympathetic and parasympathetic nervous systems. Prostate Int. 2018; 6(2):55-60.

32. Jeong JS, Ryu BH, Kim JS, Park JW, Choi WC, Yoon SW. Bojungikki-tang for Cancer-related fatigue: a pilot randomized clinical trial. Integr Cancer Ther. 2010;9(4):331-8

33. Minton O, Richardson A, Sharpe M, Hotopf M, Stone P. Drug therapy for the management of cancer-related fatigue. Cochrane Database Syst Rev. 2010;7.

34. Moss EL, Simpson JS, Pelletier G, Forsyth P. An open-label study of the effects of bupropion SR on fatigue, depression and quality of life of mixedsite cancer patients and their partners. Psychooncology. 2006;15(3):259-67.

35. Cullum JL, Wojciechowski AE, Pelletier G, Simpson JSA. Bupropion sustained release treatment reduces fatigue in cancer patients. Can J Psychiatry. 2004; 49(2):139-44.

36. Nuñez GR, Pinczowski $H$, Zanellato R, Tateyama L, Schindler F, Fonseca F, et al. Bupropion for control of hot flashes in breast cancer survivors: a prospective, double-blind, randomized, crossover, pilot phase II trial. J Pain Symptom Manag. 2013;45(6):969-79.
37. Siniscalchi A, Gallelli L, Tolotta GA, Loiacono D, De Sarro G. Open, uncontrolled, nonrandomized, 9-month, off-label use of bupropion to treat fatigue in a single patient with multiple sclerosis. Clin Ther. 2010;32(12): 2030-4.

38. Cooper JA, Tucker VL, Papakostas GI. Resolution of sleepiness and fatigue: a comparison of bupropion and selective serotonin reuptake inhibitors in subjects with major depressive disorder achieving remission at doses approved in the European Union. J Psychopharmacol. 2014;28(2):118-24.

39. Schönfeldt-Lecuona C, Connemann B, Wolf R, Braun M, Freudenmann R. Bupropion augmentation in the treatment of chronic fatigue syndrome with coexistent major depression episode. Pharmacopsychiatry. 2006;39(04): $152-4$.

40. Settle EC. Bupropion sustained release: side effect profile. J Clin Psychiatry. 1998;59(Suppl 4):32-6

41. Settle EC, Stahl SM, Batey SR, Johnston JA, Ascher JA. Safety profile of sustained-release bupropion in depression: results of three clinical trials. Clin Ther. 1999;21(3):454-63.

42. Mendoza TR, Wang XS, Cleeland CS, Morrissey M, Johnson BA, Wendt JK, et al. The rapid assessment of fatigue severity in cancer patients: use of the brief fatigue inventory. Cancer. 1999;85(5):1186-96.

43. Webster $K$, Cella D, Yost K. The F unctional a ssessment of C hronic I Inness $T$ herapy (FACIT) measurement system: properties, applications, and interpretation. Health Qual Life Outcomes. 2003;1(1):79.

44. Zigmond AS, Snaith RP. The hospital anxiety and depression scale. Acta Psychiatr Scand. 1983;67(6):361-70.

45. Sørensen J, Klee M, Palshof T, Hansen H. Performance status assessment in cancer patients. An inter-observer variability study. Br J Cancer. 1993;67(4): 773.

46. Mor V, Laliberte L, Morris JN, Wiemann M. The Karnofsky performance status scale: an examination of its reliability and validity in a research setting. Cancer. 1984;53(9):2002-7.

47. Setser A, Lacutoure M, Anadkat M, Cotliar J, Chen A, editors. NCI COMMON TERMINOLOGY CRITERIA FOR ADVERSE EVENTS UPDATED TO ENCOMPASS SKIN TOXICITIES FROM TARGETED THERAPIES. ANNALS OF ONCOLOGY; 2009: OXFORD UNIV PRESS GREAT CLARENDON ST, OXFORD OX2 6DP, ENGLAND.

48. Dana R, Spartacus RK, Mutha S, Bhat P. Seizure following chemotherapy (paclitaxel and cisplatin) in a patient of carcinoma cervix. Indian J Pharmacol. 2016;48(6):736-8.

49. Singh $G$, Rees JH, Sander JW. Seizures and epilepsy in oncological practice: causes, course, mechanisms and treatment. J Neurol Neurosurg Psychiatry. 2007;78(4):342-9.

50. Aapro M. Searching for perfection: further progress in management of chemotherapy-induced nausea and vomiting-concluding thoughts. Support Care Cancer. 2018;26(1):35-7.

51. Park B, Noh H, Choi D-J. Herbal medicine for Xerostomia in Cancer patients: a systematic review of randomized controlled trials. Integr Cancer Ther. 2018;17(2):179-91.

52. Ashrafi F, Mousavi S, Karimi M. Potential role of bupropion sustained release for cancer-related fatigue: a double-blind, placebo-controlled study. Asian Pac J Cancer Prev. 2018;19(6):1547.

53. Siu SW, Law M, Liu RK, Wong K, Soong IS, Kwok AO, et al. Use of methylphenidate for the management of fatigue in Chinese patients with cancer. Am J Hosp Palliat Med. 2014;31(3):281-6.

54. Jean-Pierre P, Morrow GR, Roscoe JA, Heckler C, Mohile S, Janelsins M, et al. A phase 3 randomized, placebo-controlled, double-blind, clinical trial of the effect of modafinil on cancer-related fatigue among 631 patients receiving chemotherapy: a University of Rochester Cancer Center Community Clinical Oncology Program Research base study. Cancer. 2010;116(14):3513-20.

55. Moraska AR, Sood A, Dakhil SR, Sloan JA, Barton D, Atherton PJ, et al. Phase III, randomized, double-blind, placebo-controlled study of long-acting methylphenidate for cancer-related fatigue: north central Cancer treatment group NCCTG-N05C7 trial. J Clin Oncol. 2010;28(23):3673.

56. Bruera E, El Osta B, Valero V, Driver LC, Pei B-L, Shen L, et al. Donepezil for cancer fatigue: a double-blind, randomized, placebo-controlled trial. J Clin Oncol. 2007;25(23):3475-81.

57. Bergin A, Hovey E, Lloyd A, Marx G, Parente P, Rapke T, et al. Docetaxelrelated fatique in men with metastatic prostate cancer: a descriptive analysis. Support Care Cancer. 2017;25(9):2871-9.

58. Roscoe JA, Morrow GR, Hickok JT, Mustian KM, Griggs JJ, Matteson SE, et al. Effect of paroxetine hydrochloride $\left(\right.$ Paxil $\left.{ }^{\oplus}\right)$ on fatigue and depression in 
breast cancer patients receiving chemotherapy. Breast Cancer Res Treat. 2005;89(3):243-9.

59. Lesser GJ, Case D, Stark N, Williford S, Giguere J, Garino LA, et al. A randomized double-blind, placebo-controlled study of oral coenzyme Q10 to relieve self-reported treatment related fatigue in newly diagnosed patients with breast cancer. J Support Oncol. 2013;11(1):31.

60. Lesser G, Case L, Stark N, Williford S, Giguere J, Garino A, et al. A randomized double-blind placebo-controlled study of oral coenzyme Q10 to relieve self-reported cancer-treatment-related fatigue in newly diagnosed breast cancer patients. J Clin Oncol. 2010;28(15_suppl):9006.

61. Blackhall L, Petroni G, Shu J, Baum L, Farace E. A pilot study evaluating the safety and efficacy of Modafinil for Cancer-related fatigue. J Palliat Med. 2009;12(5):433-9.

62. Gullett JM, Cohen RA, Yang GS, Menzies VS, Fieo RA, Kelly DL, et al. Relationship of fatigue with cognitive performance in women with earlystage breast cancer over 2 years. Psychooncology. 2019;28(5):997-1003.

\section{Publisher's Note}

Springer Nature remains neutral with regard to jurisdictional claims in published maps and institutional affiliations.

Ready to submit your research? Choose BMC and benefit from:

- fast, convenient online submission

- thorough peer review by experienced researchers in your field

- rapid publication on acceptance

- support for research data, including large and complex data types

- gold Open Access which fosters wider collaboration and increased citations

- maximum visibility for your research: over $100 \mathrm{M}$ website views per year

At BMC, research is always in progress.

Learn more biomedcentral.com/submissions 